\title{
Hoslundia opposita and other Nigerian plants inhibit sickle hemoglobin polymerization and prevent erythrocyte sickling: a virtual screening-guided identification of bioactive plants.
}

${ }^{1}$ Eric O. Olori., ${ }^{2,3}$ Olujide O. Olubiyi., ${ }^{1}$ Chinedum P. Babalola

${ }^{1}$ Department of Pharmaceutical Chemistry, Faculty of pharmacy, University of Ibadan, Ibadan

${ }^{2}$ Department of Pharmaceutical Chemistry, Faculty of pharmacy, Obafemi Awolowo University, Ile-Ife.

${ }^{3}$ Institute of Biological Information Processing (IBI-7), Forschungszentrum Julich, 52425, Germany.

\begin{abstract}
In sickle cell disease, a hereditary hemoglobinopathy, clinically observed disease presentations are the endpoint of a point mutation involving the substitution of glutamic acid with valine at the position 6 of the beta globin chain. With about 4.4 million people globally being affected, and another 43 million people bearing the sickle cell trait, several research efforts have been made to discover new and affordable treatment and possibly cure for the disease. Africa is endowed with a large flora population and traditional healers and citizens have over time depended on the use of herbs in folkloric medicine for different ailments including sickle cell disease (SCD). Such native knowledge has often formed the basis for different research exploration into the anti-sickling activities of selected African plants. These plants that have been so far investigated for their anti-sickling properties represent about $0.05 \%$ of the 45,000 plant species enriching the flora landscape in Sub-Saharan Africa. Some of these have yielded potent anti-sickling profiles. In the current work we seek to achieve a more extensive search of the African plant diversity with anti-sickling properties: for this we have adopted a hybrid computational-cum-experimental protocol that employed computer-aided drug design (CADD) means for identifying plants with at least one constituent capable of interacting with the sickle hemoglobin, followed by extractive procedures and anti-sickling experiments for validating the predictions. Over two thousand (or 2,000) African natural products, representing over 200 plant species, were first virtually screened against the crystal structure of the dimerized human sickle hemoglobin. The natural products with the best computed sickle hemoglobin interaction energetics were found to belong to five plant species including Catharanthus roseus, Rauvolfia vomitoria, Hoslundia opposita, Lantana camara and Euphorbia hirta. The leaves of these plants were each collected subsequently and subjected to standard processing and extraction procedures. Using both HbSS polymerization inhibition and sickling reversal tests significant reductions in polymerization of erythrocyte hemolysate of the HbSS genotype were observed with the methanolic extracts of the plants, as well as sickling reversal levels of up to $68.50 \%$ (H. opposita) was observed.
\end{abstract}

Keywords: Sickle cell disease, sickle haemoglobin, computer aided drug design, Autodock, virtual screening, haemoglobin polymerization, anti-sickling. 


\section{Introduction}

Sickle cell disease (SCD) is a blood disorder affecting the red blood cells and is inherited (NHLBI, 2015). The disease was reported to be majorly prevalent in resource limited countries and about $80 \%$ of SCD cases occur in sub-Saharan Africa (Rees, 2010). Globally about 4.4 million people have SCD while 43 million bear the sickle cell trait (GBD, 2015) In 2010, the birth of children with sickle cell anemia (SCA) accounted for $2.4 \%$ the world's most severe cases of the disease (Piel FB et al, 2013a). However, worrying estimates indicate that the number of newborns with SCA will increase from approximately 305,000 in 2010 to 404,000 in 2050 (Piel FB et al, 2013b \& Piel FB et al, 2017). About 300,000 babies are born worldwide with sickle cell disease each year, spread across Africa and India (Piel et al, 2015). In 2010, 90,000 births with sickle cell disease were estimated in Nigeria and 40,000 in the Democratic Republic of Congo (Piel et al, 2013). Another estimated 40,000 children affected with sickle cell disease are born in India each year, 10,000 in the Americas, 10,000 in the Eastern Mediterranean, and 2000 in Europe (Piel FB et al, 2013). Newborn screening programs in the United States, Jamaica, and Europe have documented the utility of early identification of SCA, with a marked reduction in morbidity and mortality, especially in the first 5 years of life (Rogers et al. 1978; Vichinsky et al. 1988; Almeida et al. 2001; Bardakdjian-Michau et al). Sickle cell anaemia resulting from SCD is characterized by abnormality in the oxygen carrying haemoglobin (haemoglobin $\mathrm{S}, \mathrm{HbS}$ ) which at the molecular level results from a point mutation replacing a charged and hydrophilic glutamic acid with hydrophobic valine at the position 6 of the beta globin polypeptide chain (Pauling L et al, 1949 \& Ingram VM, 1957). Under deoxygenation conditions (low oxygen tension), the mutant $\mathrm{HbS}$ polymerizes inside the red blood cells (RBCs) into a stiff gel and further into fibers leading to a decrease in red blood cell (RBC) deformability. HbS polymerization within erythrocytes provokes an alteration in the functional shape of red cells from the normal spherical form into distorted shapes some of which resemble a sickle (Bisnu et al, 2013 \& Herrick, 1910). With the HbS molecule occupying a central position in disease development, it makes sense that efforts to evolve new leads for SCD management should, as a viable option, consider the inhibition of $\mathrm{HbS}$ polymerization both by small molecules (Ismaila O. Nurain, 2017) and larger molecular weight peptide-based inhibitors (Olubiyi et al, 2019). For instance, the recently FDA-approved voxelotor is a covalent modifier of $\mathrm{HbS}$ molecule and acts as an allosteric modulator stabilizing the hemoglobin molecule in its non-aggregating R-conformer (Vichinsky et al, 2019).

Normal hemoglobin has a quaternary structure existing as a tetrameric protein unit with two alpha- and two beta-chains (Robert J et al, 2014) with each of the four chains covalently linked to a heme molecule. There are 141 and 146 amino acids in the $\alpha$ and $\beta$ chains of hemoglobin, respectively (Robert $\mathrm{J}$ et al, 2014). While interactions between multiple hemoglobin tetrameric units can in principle result in polymerization, such resulting aggregates are however unstable under normal physiological conditions. In homozygous SS patients on the other hand, the beta-chains contain valine at the sixth position which is able to form hydrophobic contacts with similarly uncharged hydrophobic residues like Phe85 and Leu88 of the adjacent beta globin chain. These contacts constituting the lateral $\mathrm{HbS}$ contacts are secondarily stabilized by other contacts involving segments of the hemoglobin molecule that are remote from the valine 6 mutation. Taken together, these contacts constitute the basis for $\mathrm{HbS}$ polymerization and by 
extension SCD symptom complex development. Within the same beta-2 globin chain of an $\mathrm{HbS}$ molecule there is glutamic acid at position 121 which interacts with Gly16 of the beta-1 globin chain of another $\mathrm{HbS}$ molecule. And, between these two $\mathrm{Hb}$ molecules, His20 from alpha-2 globin chain interacts with Glu6 of beta-1 of the third hemoglobin molecule as part of the axial contacts. Apart from beta-2 globin's Val6 interacting with Phe85 and Leu88 of the adjacent beta globin chain, Asp73 and Thr4 from the two beta globin chains are also involved in contacts (Marengo-Rowe, 2006 \& Levasseur DN et al, 2004) Glu121 from beta-1 chain and Pro114 of alpha-2 and His116 of beta-2 globin chain also form interaction (Ferrone, F. A et al, 1985 \& Ivanova, M, 2002). Within the lateral contact, the hydrophobic Val6's side chain fits well into a hydrophobic pocket formed by $\beta$-Leu 88 leucine and $\beta$-Phe85 residues on an adjacent beta globin chain (Ivanova $\mathrm{M}$ et al, 2000).

Sickle cell disease is embodied by serious hemorheological irregularities which play a role in the pathophysiology of various severe and chronic complications. Normal RBC are pliable, able to squeeze through tight capillary junctions and can live for 90 to 120 days. During a typical 120 days lifespan of a RBC, it circulates through arteries, veins and small capillaries traveling -in total- a distance of $500 \mathrm{~km}$ (Lasch et al., 2000). Because sickle RBCs have stiffened texture they cannot as readily change their shape; the stress of squeezing through tight vascular junctions contributes to their tendency to hemolyze and as a result sickle RBCs last only 10 to 20 days, hence the associated anemia. Common signs and symptoms of the disease include painful swelling (hands and feet; vaso-occlusive crisis), fatigue from anemia (aplastic crisis), yellowing of the skin and white of the eyes, infections (splenic sequestration crisis), fever, chest pain and difficulty in breathing (acute chest syndrome), hemolytic crisis (Serjent GR, 2001 \& Kar BC, 1991). While bone marrow cell transplant is the only available curative treatment of SCD (NHLBI, 2002), the following treatments are also available in the management of SCD: vaccination, antibiotics (for the infection component), high fluid intake, folic acid supplementation analgesic (e.g. Ibuprofen), hydroxyurea, blood transfusion and herbal preparations. Hydroxyurea has been proven to decrease the number of SCD crisis (American Society, 2016). Mechanistically it stimulates the production of fetal hemoglobin ( $\mathrm{HbF}$ ) and which inhibits $\mathrm{HbS}$ aggregation and has also been found to reduce white blood cells component of the inflammation crisis (Lanzkron S et al, 2008). The health-care cost of the management of SCD patients is disproportionately high compared to the number of people afflicted by the disease and considering that most affected individuals are below the poverty line and unable to afford the high-cost of treatment. This in particular creates the urgent need for the unraveling of potentially cheap natural products and plants-based treatment options. (Bisnu et al, 2013). One of such efforts produced Niprisan $^{\mathbf{T M}}$, a herbal preparation developed at the Nigerian Institute for Pharmaceutical Research and Development (NIPRD) and indicated for the treatment of SCD. Niprisan was formulated from the ethanolic extract of Piper guineense seeds, Pterocarpus osum stem, Eugenia caryophylius fruit and Sorghum bicolor leaves. About 45,000 plant species are found in Sub-Saharan Africa (Klopper, R. R et al, 2007) and only about $0.05 \%$ has been researched and found to possess desirable antisickling properties. According to Sunday J. Ameh, discovery of more effective antisickling plants from the largely untapped African flora wealth will require the use of more innovative strategies (Ameh et al, 2012). It is certainly not far-fetched to expect that many more plants with more potent antisickling components exist in the African floral population that are yet undiscovered and the challenge remains how to efficiently identify these in eco-compatible ways. In this work we propose a protocol relying on the structural understanding of $\mathrm{HbS}$ aggregation for targeted screening of natural products from African plants against a virtual model of the $\mathrm{HbS}$ macromolecule. Our design strategy is based 
on the double nucleation aggregation mechanism of the $\mathrm{HbS}$ molecule. We believe that natural products capable of forming a precise fit into Val6 binding cavity on the lateral aggregation surface of the $\mathrm{HbS}$ molecule will be able to delay the formation of a critical $\mathrm{HbS}$ nucleus (homogenous nucleation), which in turn is capable of preventing template-driven nucleation altogether and thus preventing aggregation. Using this protocol we identified Nigerian plants containing the natural products shown in our computational drug design work; these were collected and subjected to in vitro antisickling and polymerization reversal assays. To the best of the knowledge of the authors, this work represents the first computer-guided selection of plants for screening of plants for antisickling activities.

Many researches have been conducted by various researchers in recent times to find new drugs from natural products for the treatment of SCD using traditional screening methods of drug discovery. These screening methods are time consuming and costly. For example Olufunmilayo et al in 2010 evaluated the antisickling activities of Plumbago zeylanica and Uvaria chamae. Wambebe et al. (2001) reported the use of combination of Piper guinensis, Pterocarpa osun, Eugenia caryophylla and Sorghum bicolor extracts for the treatment of SCD. Extracts of Pterocarpus santolinoides and Aloe vera were reported to increase the gelling time of sickle cell blood and inhibit sickling in vitro (Ugbor, 2006). Sofowora and Isaac- Sodeye (1971) reported the reversal of sickling by root extracts of Fagara zanthoxylloides. Thomas et al in 1987 reported the use of an aqueous extract of the unripe fruit of pawpaw (Carica papaya) as a treatment for sickle cell disease patients during crises. The research reported the reversal and inhibition of sickling of HbSS red blood cells using aqueous extract. Moody et al. (2003) reported that the aqueous extracts of the reddish brown freshly fallen leaves of Terminalia catappa were able to exhibit antisickling activity on sodium metabisulfite induced sickling. Fractionation of an aqueous extract of root bark from Fagara xanthoxyloides by column chromatography on DEAE-A-50, utilizing an elution gradient of $\mathrm{pH}$ 7.5-5.0, yielded five fractions. All fractions reversed metabisulfite-induced sickling in vitro of erythrocytes homozygous for hemoglobin $\mathrm{S}$ (Abu S et al, 1981). Boiled and crude ethanolic extracts of edible Cajanus cajan beans were prepared and used for in vitro studies involving blood samples obtained from confirmed sickle cell (HbSS) patients. It was demonstrated that the extracts were able not only to inhibit sickling in sodium metabisulfite solution but also quickly reverted to normal morphology of already sickled erythrocytes (Osuagwu CG, 2010).

While all of the aforementioned research investigations were based on prior knowledge of the ethno-medicinal use of the studied plants, in the present investigation we have employed a protocol that relies exclusively on the calculated thermodynamic and structure interaction of over 2000 African natural products with 3D X-ray crystallographic model of human sickle hemoglobin. Because our computer aided drug design (CADD)-guided search for African plants with anti-sickling properties is not based on knowledge of the plants' ethno-medicinal value, we have been able to conduct a more objective search for the desired activity initialized by virtually screening thousands of natural products before performing antisickling assays. We additionally present an ADME model of the top-performing natural products to properly conceptualize the cell-free and cell-based validation assays presented here.

\section{Materials and Methods}


A number of scientific article databases and repositories including the National Center for Biotechnology Information (NCBI), Pubmed, Chemspider, Pubchem, CHEBI, were searched using different combinations of search terms like "Nigerian plants", "African plants, "Chemical constituents", "Chemical structure", "X-ray", "Mass spectrometry" and " Nuclear magnetic resonance". Articles and records satisfying the search criteria and containing structural information about African natural products were downloaded and further processed. From the 2D structural information of about 2000 natural products covering some two hundred different plant species the 3D structural coordinates were generated using the ligand modeling software ChemBioOffice (Cousins, K.R, 2005). Special attention was accorded to stereogenic sites and the resulting models were subjected to geometric optimization via energy minimization scheme using the integrated MOPAC algorithm (Cousins, K.R, 2005). This helped eliminate steric clashes and allowed each configuration to attain a potential energy minimum. The optimized 3D models were then saved in the Protein Data Bank (PDB) format and pooled together to form the virtual screening library employed in this work.

\section{Hemoglobin S structure and conformational sampling}

The X-ray crystallographic structure (2HBS.pdb) (Harrington et al, 1997) of the dimerized human sickle haemoglobin was downloaded from the RCSB website (https://www.rcsb.org). The structure is a homotetramer involving one tetramer unit (two $\alpha$ and two $\beta$ globin subunits) interacting with another tetramer unit (Harrington, et al, 1997). The two tetramer units form contact via an interacting surface involving amino acids contributed from two $\beta$ globin subunits (one from each tetramer). The $\beta$ globin subunit from Tetramer 1 bears the Glu6Val mutation, while the $\beta$ globin subunit of Tetramer 2 provides an hydrophobic cavity (both shape and charge complementarity) that Val6 perfectly fits into. The $\beta$ globin subunit of Tetramer 2 that provides the cavity was thus taken as the receptor molecule since the aim was to competitively inhibit Val6 docking at this site. Preliminary explicit solvent molecular dynamics (MD) simulation had been performed to establish the structural integrity of the Val6 acceptor chain, and the receptor was shown to be stable over a $100 \mathrm{~ns}$ MD trajectory performed at $300 \mathrm{~K}$ (Olubiyi et al, 2018).

\section{Virtual screening}

Using the software Autodock tool (O.Trott, 2010) and Autodock Vina (O.Trott, 2010), each energy-minimized natural product in our virtual library was docked in a virtual screening protocol into the $\beta$ globin's Val6 binding site defined by a hyper-rectangular grid with $\mathrm{x}, \mathrm{y}, \mathrm{z}$ dimension $15.00 \AA, 18.75 \AA, 15.00 \AA$. The grid was centered at $6.215,57.373,22.171 \AA$ to overlap Leu28, Leu42, Leu92, Leu106, Leu110, Leu137, and Leu141, Phe41, Phe71, Phe91, His63, Lys66, and Val67 residues on the Val6 acceptor beta globin molecule and chain B in the crystallographic structure (O.Trott, 2010). The computed binding energies were collected and analyzed to identify the natural products (and hence plants) with the best potential to form thermodynamically stable binding interaction with the HbS lateral aggregation surface.

\section{Plant collection, botanical authentication and processing}

Five out of the seventeen plants identified via virtual screening were collected based on availability and within the time frame from different parts of Nigeria. Rauvolfia vomitoria Afzel. 
and Lantana camara L. leaves were collected in Agulu, Anambra State Nigeria while the leaves of Catharanthus roseus (L.) G.Don, Hoslundia opposita Vahl and Euphorbia hirta L. were collected in Iyamho, Edo State, Nigeria. They were identified and authenticated at the Department of Botany, Faculty of Sciences, University of Ibadan, Nigeria with voucher numbers 22924, 22925, 22926, 22927 and 22928 for Hoslundia opposita, Euphrobia hirta, Rauvolfia vomitoria, Lantana camara and Catharanthus roseus respectively. The plants were deposited in the herbarium of the department. The leaves of the collected plants were air-dried in the laboratory and pulverized into powder using an electrical grinder (750 Watts Euro Premium, Tango DX). 100g of each plant sample was first extracted with n-hexane for three days. Following filtering the residue was extracted with methanol (Analytical grade, Sigma-Aldrich) for 5 days which was then filtered and the filtrate concentrated using a rotary evaporator (DVB RE 100-pro). The concentrates were freeze-dried using a freeze dryer (Zhengzhou Laboao Instrument, LFD-10) and stored at $-20^{\circ} \mathrm{C}$. The percentage yields were calculated as $7.1 \%, 1.6 \%$, $5.0 \%, 5.4 \%$ and $1.99 \%(\mathrm{w} / \mathrm{w})$ for Catharanthus roseus, Rauvolfia vomitoria, Hoslundia opposita, Lantana camara and Euphorbia hirta respectively.

$$
\% \text { Yield }=\frac{\text { Weight of extract }}{\text { Weight of powder extracted }} X 100
$$

\section{Antisickling assay}

\section{Collection of blood}

Human blood sample was collected from the residual blood samples obtained from sickle cell clinic at the University College Hospital, Ibadan. The collected blood was centrifuged, washed with phosphate buffer saline $\mathrm{pH}$ : 7.4 (PBS: $1.3 \mathrm{M} \mathrm{NaCl}, 0.07 \mathrm{MNa}_{2} \mathrm{HPO}_{4}$ and $0.03 \mathrm{M} \mathrm{NaH}_{2} \mathrm{PO}_{4}$ ) at $4000 \mathrm{rpm}$ for 5 minutes using cold centrifuge.

\section{Polymerization Inhibition Test}

Polymerization inhibition test was carried out using a modified method previously described by Iwu et al. (1988) and Chikezie et al 2011). This procedure is based on the principle that HbS molecules undergo gelation (gel formation) under deoxygenation conditions induced by the presence of sodium metabisulfite acting as reductant; under this condition deoxyHbS molecules predominate. The degree of polymerization was measured by recording the time-dependent increments in the absorbance of the assay mixture. $0.1 \mathrm{ml}$ of washed $\mathrm{HbS}$ was measured into a test tube and equal volume of distilled water was added to lyse the blood cells. $0.5 \mathrm{ml}$ and $1.0 \mathrm{ml}$ volumes of Phosphate buffer saline (PBS) were added to a test tube. The content was transferred to a cuvette and $3.4 \mathrm{ml}$ of $2 \%$ aqueous solution of sodium metabisulfite was added. The absorbance of the mixture was recorded at time zero using a UV/Visible Spectrophotometer (Biobase, BK-UV1800PC) (wavelength $=700 \mathrm{~nm}$ ) and at a 30 seconds interval for a total of 180 seconds (control assay). This procedure was repeated by substituting $1.0 \mathrm{ml}$ of PBS with $1.0 \mathrm{ml}$ of each of the plant extracts at $2 \mathrm{mg} / \mathrm{ml}, 5 \mathrm{mg} / \mathrm{ml}$ and $10 \mathrm{mg} / \mathrm{ml}$ ) (test assay). Percent polymerization was then calculated as:

$$
\% \text { Polymerization }=\frac{A t / c}{A c 180 t h \sec } X 100
$$

Where: At/c $=$ Absorbance of test/control assay at time $=\mathrm{t}(\mathrm{s})$.

Ac $180^{\text {th }} \mathrm{sec}=$ Absorbance of control assay at the $180^{\text {th }} \mathrm{sec}$. 


\section{Sickling reversal test}

Sickling reversal test was carried out using the method previously described by Pauline $\mathrm{N}$ et al, 2013. $20 \mu \mathrm{L}$ of washed red blood cells was pipetted into a clean Eppendorf tube using a micro pipette. $20 \mu \mathrm{L}$ of PBS was then added to the Eppendorf tube containing the washed blood. 680 $\mu \mathrm{L}$ of freshly prepared $2 \%$ sodium metabisulfite was added and incubated in a thermostated water bath at $37^{\circ} \mathrm{C}$ for $1 \mathrm{~h} .200 \mu \mathrm{L}$ of distilled water was added after the initial incubation period and incubated for another $1 \mathrm{~h}$ at $37{ }^{\circ} \mathrm{C} .10 \mu \mathrm{L}$ of the incubated cells was transferred onto a hemocytometer. The cells were counted at five different zones (Control assay). This procedure was repeated by replacing $200 \mu \mathrm{L}$ of distilled water added after the first incubation with $200 \mu \mathrm{L}$ each of the extract at three different concentrations (10,5 and $2 \mathrm{mg} / \mathrm{ml})$. The cells were categorized as normal or sickle using visual inspection of their shapes. Biconcave or disk-like shapes were taken to be normal while the elongated, star-like, or wrinkled shapes were considered sickle. The percentage sickle cells were calculated using the following formula:

$\%$ Sickling $=\frac{\text { Number of sickle cells }}{\text { Total number of counted cells }} X 100$

\section{Results and discussion}

Chemical diversity of the natural products generated

Structures for the 2000 compounds comprising alkaloids, flavonoids, anthraquinones, terpenoids, steroids and coumarins were generated from 200 African plant species (Fig 1). The best performing twenty-three compounds with binding energies ranging from $-7.0 \mathrm{kcal}$ to $-7.6 \mathrm{kcal} / \mathrm{mol}$ from seventeen plant species are presented in Table 1

Table 1: Identified natural products from docking

\begin{tabular}{|l|r|l|l|c|}
\hline \multicolumn{1}{|c|}{ Plant Source } & S/N & Natural product & \multicolumn{1}{|c|}{$\begin{array}{c}\text { 2D structure of } \\
\text { natural product }\end{array}$} & $\begin{array}{c}\text { Binding } \\
\text { affinity } \\
\text { (Kcal/mol) }\end{array}$ \\
\hline $\begin{array}{l}\text { Alangium salvifolium } \\
\text { (L.F) Wang }\end{array}$ & 1. & Alangimarckine & -7.6 \\
\cline { 2 - 5 } & 2. & Alangimaridine & & -7.5 \\
& 3. & Alangicine & & \\
& & & &
\end{tabular}




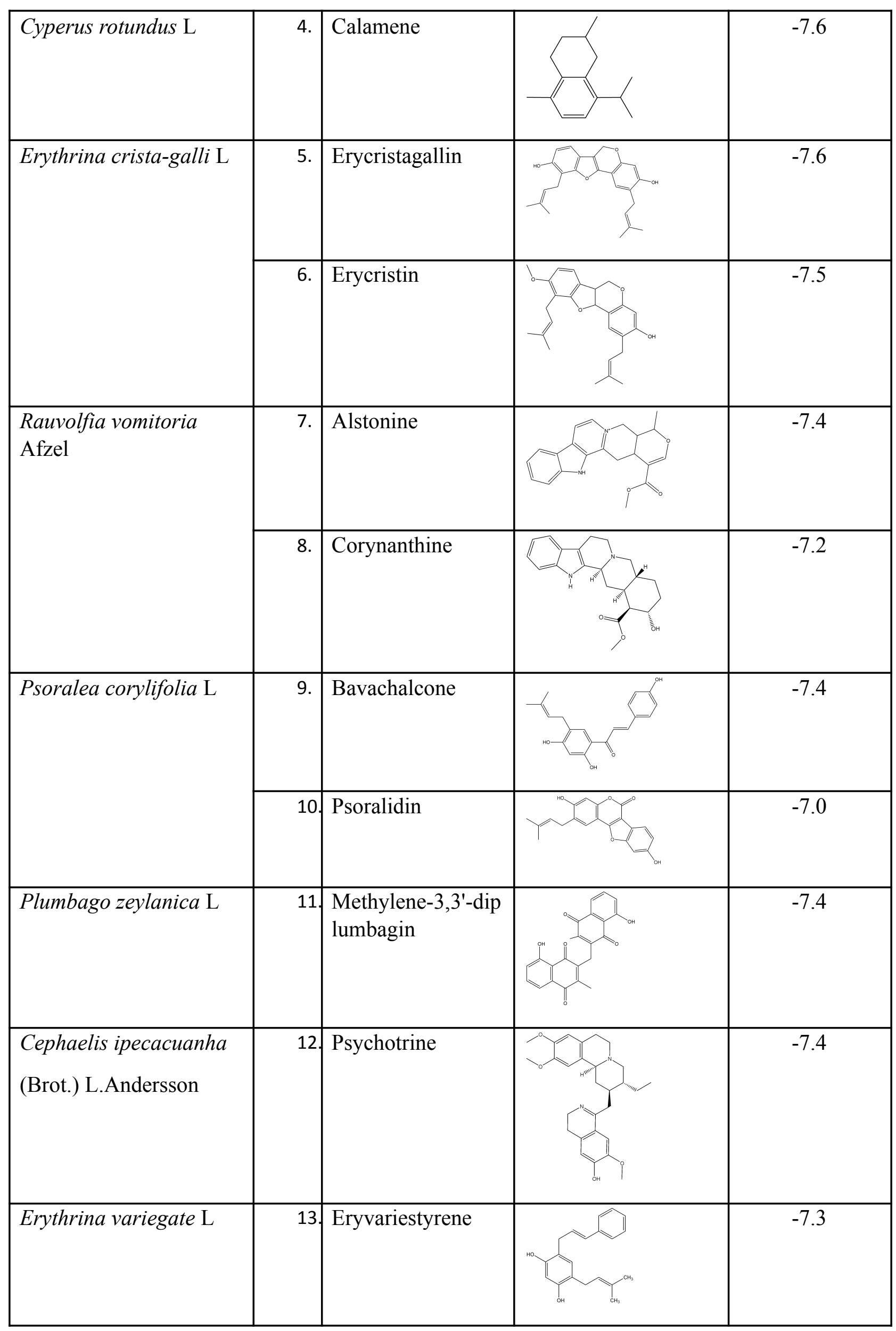


bioRxiv preprint doi: https://doi.org/10.1101/2021.07.25.453693; this version posted July 26, 2021. The copyright holder for this preprint (which was not certified by peer review) is the author/funder, who has granted bioRxiv a license to display the preprint in perpetuity. It is made available under aCC-BY-NC-ND 4.0 International license.

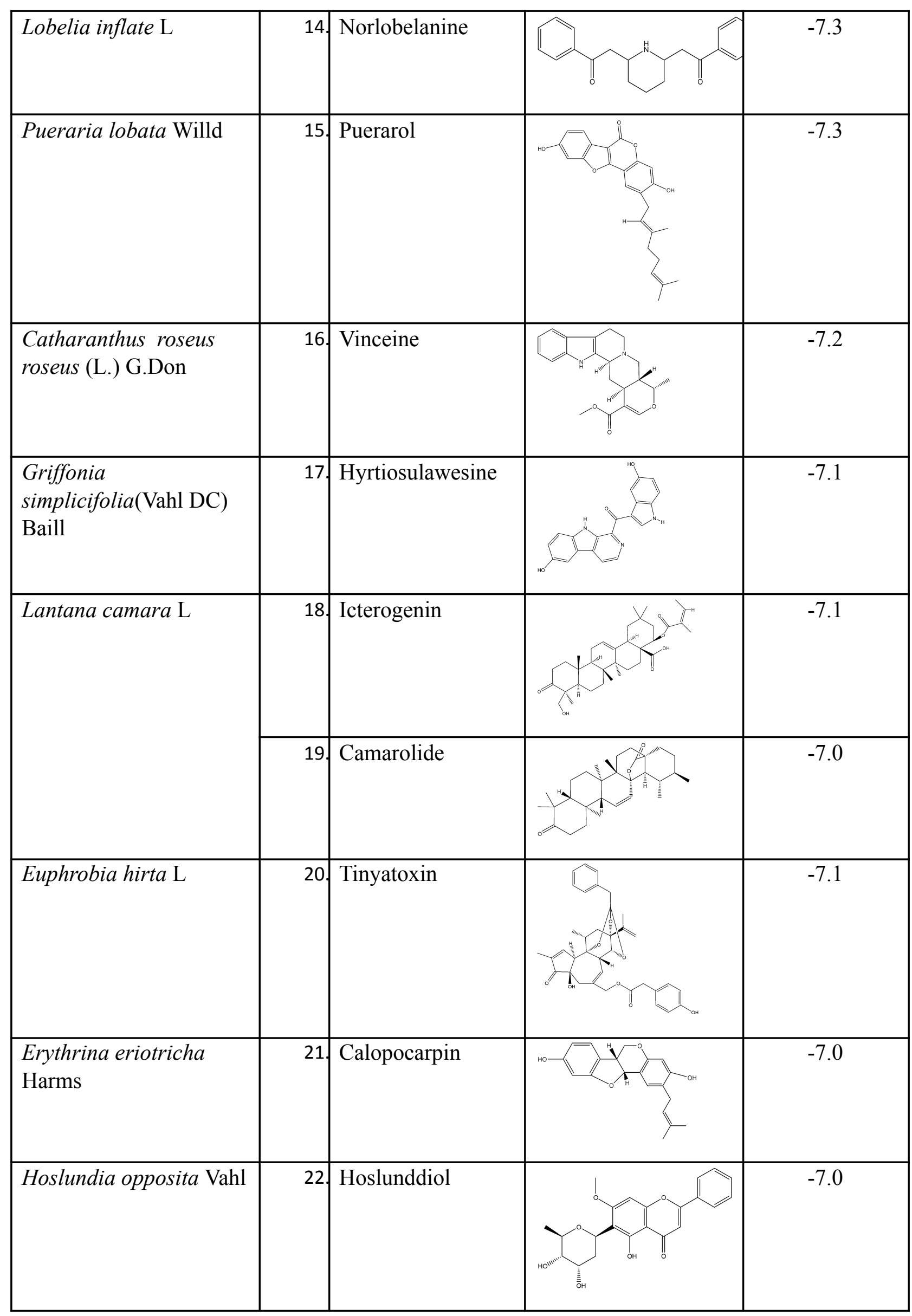




\begin{tabular}{|l|l|l|l|}
\hline Ajuga decumbens & 23. Toddalosin & -7.0 \\
Thunb & &
\end{tabular}

It is worthy of note to report that some of the natural products with strong binding $\mathrm{HbS}$ interaction identified via blind virtual screening in this work are found in plants that had either previously been employed ethnomedicinally in SCD treatment or that have been reported to possess antisickling properties. Interestingly, the knowledge of their use in SCD treatment and their anti-sickling properties was unknown to us at the point of natural product library design since the choice of natural products was not based on antisickling properties or use of the plants. For example Olufunmilayo et al in 2010 published a paper in which Plumbago zeylanica was confirmed to possess anti-sickling properties. The work however did not offer information about the plant constituent(s) responsible for the observed anti-sickling activity. In the present work, we propose that methylene-3,3'-diplumbagin, a naphthaquinone found in the root of $P$. zeylanica with binding free energy of $-7.4 \mathrm{Kcal} / \mathrm{mol}$ is possibly one of the constituents responsible for the reported activity. In another work, Egunyomi et al (2009) investigated the anti-sickling activities of two ethnomedicinal plant recipes used for the management of sickle cell anemia in Ibadan, Nigeria (Egunyomi et al, 2009) and Rauvolfia vomitoria was one of the plants present in the investigated recipes. Two alkaloids, alstonine and corynanthine found in the leaves of the plant exhibited strong computed binding interaction with $\mathrm{HbS}$ molecule with binding free energy

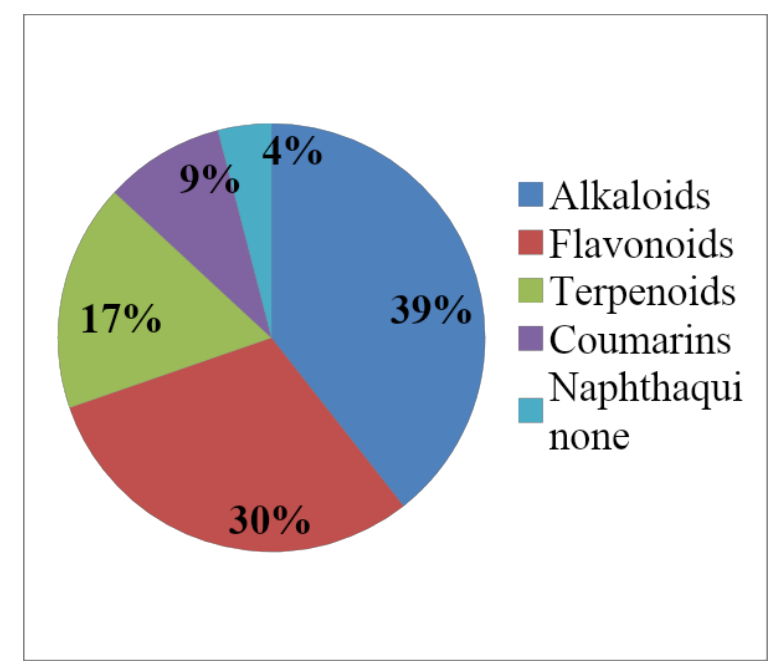

Figure 1: Distribution of the identified compounds into the class of natural products they belong

values of -7.4 and $-7.2 \mathrm{kcal} / \mathrm{mol}$, respectively. Their strong binding interaction suggests that they are likely responsible for the earlier reported antisickling activity of the plant. Diosmin and fagarol with binding free energy values of -6.3 and $-6.1 \mathrm{Kcal} / \mathrm{mol}$, respectively found in the current exploratory investigation are constituents of Fagara zanthoxyloides that had previously been reported by Sofowora et al, in 1971 to possess antisickling activity (Sofowora, et al, 1971). Chikezie, reported Psidium guajava as possessing $\mathrm{HbS}$ polymerization inhibitory at different 
investigated concentrations. Tamarixetin, gossypetin and guajaverin with binding free energy values of $-6.1 \mathrm{kcal} / \mathrm{mol},-5.8 \mathrm{kcal} / \mathrm{mol}$ and $-5.7 \mathrm{kcal} / \mathrm{mol}$ respectively found in the current investigation are constituents of the plant likely to be responsible for the inhibitory effect. Iwu et al (1988) and Ismaila O. Nurain, et al, 2017 in separate investigations reported Cajanus cajan as having antisickling activity (74). In our work, two of its constituents, cajanine and cajanulactone were found with binding free energy values $-5.9 \mathrm{Kcal} / \mathrm{mol}$ and $-5.8 \mathrm{Kcal} / \mathrm{mol}$, respectively. We also identified carpaine with binding free energy of $-5.9 \mathrm{kcal} / \mathrm{mol}$ which is one of the antisickling constituents of Carica papaya earlier reported by Thomas et al, 1987 and Imaga et al, 2009.

\section{Polymerization inhibition test}

The antisickling assay confirmed the ability of the plants collected to both inhibit $\mathrm{HbS}$ polymerization and to reduce the extent of $\mathrm{RBC}$ sickling. This procedure used to test the antisickling properties of the plant extracts is based on the principle that $\mathrm{HbS}$ molecules undergo gelation when deprived of oxygen, transiting to deoxyHbS molecules. Sodium metabisulfite induces polymerization and was hence used as the reductant. The level of polymerization was measured by recording increasing absorbance of the assay mixture with progression of time.

Table 2: Percentage polymerization of erythrocyte hemolysate of HbSS genotype in the presence of methanolic extracts of $H$. opposita, $C$. roseus and R.vomitoria at different concentrations

\section{Polymerization (\%)}

\begin{tabular}{|c|c|c|c|c|c|c|}
\hline \multirow{2}{*}{ Time (s) } & \\
\hline & 30 & 60 & 90 & 120 & 150 & 180 \\
\hline Control & $100.00 \pm 0.00$ & $100.00 \pm 0.00$ & $100.00 \pm 0.00$ & $100.00 \pm 0.00$ & $100.00 \pm 0.00$ & $100.00 \pm 0.00$ \\
\hline \multicolumn{7}{|c|}{ H. opposita } \\
\hline 10ppm & $45.29 \pm 7.78 *$ & $45.90 \pm 7.47 *$ & $46.37 \pm 7.40 *$ & $46.37 \pm 7.54 *$ & $46.50 \pm 7.70 *$ & $46.00 \pm 7.64 *$ \\
\hline $5 \mathrm{ppm}$ & $72.96 \pm 3.83 *$ & $74.09 \pm 3.20 *$ & $74.69 \pm 3.02 *$ & $76.00 \pm 2.27 *$ & $75.95 \pm 2.45 *$ & $75.53 \pm 2.31 *$ \\
\hline $2 \mathrm{ppm}$ & $78.15 \pm 5.22 *$ & $78.54 \pm 5.92 *$ & $78.77 \pm 6.13 *$ & $78.69 \pm 5.54 *$ & $78.76 \pm 5.19 *$ & $80.94 \pm 8.58 *$ \\
\hline \multicolumn{7}{|l|}{ C. roseus } \\
\hline 10ppm & $74.06 \pm 4.15^{*}$ & $75.49 \pm 4.10 *$ & $74.77 \pm 6.18^{*}$ & $75.42 \pm 5.52 *$ & $75.30 \pm 4.33 *$ & $75.05 \pm 5.81 *$ \\
\hline $5 p p m$ & $85.23 \pm 4.56^{*}$ & $85.71 \pm 4.48 *$ & $86.22 \pm 4.54 *$ & $86.06 \pm 4.47 *$ & $85.72 \pm 4.56^{*}$ & $85.97 \pm 4.41 *$ \\
\hline $2 \mathrm{ppm}$ & $86.45 \pm 5.05 *$ & $86.15 \pm 4.59 *$ & $86.19 \pm 5.26^{*}$ & $86.23 \pm 4.99 *$ & $86.37 \pm 4.22 *$ & $86.53 \pm 4.11 *$ \\
\hline \multicolumn{7}{|l|}{$\begin{array}{l}R . \\
\text { vo }\end{array}$} \\
\hline 10ppm & $\begin{array}{l}55.61 \\
15.85 *\end{array}$ & $\begin{array}{l}54.51 \\
14.55 *\end{array}$ & $\begin{array}{l}54.26 \\
14.76 *\end{array}$ & $\begin{array}{l}54.13 \\
14.37 *\end{array}$ & $\begin{array}{l}53.66 \\
14.26 *\end{array}$ & $\begin{array}{l}54.17 \\
15.88 *\end{array}$ \\
\hline $5 \mathrm{ppm}$ & $78.64 \pm 6.69 *$ & $78.68 \pm 6.83 *$ & $78.40 \pm 5.90 *$ & $78.43 \pm 5.96 *$ & $77.95 \pm 6.09 *$ & $77.71 \pm 6.63 *$ \\
\hline $2 \mathrm{ppm}$ & $83.03 \pm 4.10 *$ & $84.38 \pm 4.07 *$ & $84.91 \pm 4.04 *$ & $84.89 \pm 3.95 *$ & $84.53 \pm 4.22 *$ & $84.21 \pm 4.56 *$ \\
\hline
\end{tabular}

Values are expressed as Mean \pm Standard deviation of mean. $n=5$.

${ }^{*} \mathrm{p}<0.01$ (When compared with control). 
A close look at Table 1 shows that all tested extracts show a reduction in polymerization when compared with the control assay. This displays their anti-sickling properties. Methanolic extract of Hoslundia opposita (Table 1) shows a significant $(\mathrm{p}<0.01)$ dose-dependent reduction of polymerization to $46.07 \pm 0.45 \%, 74.87 \pm 1.20 \%$, and $78.98 \pm 0.99 \%$ at three different concentrations of $10 \mathrm{ppm}, 5 \mathrm{ppm}$ and $2 \mathrm{ppm}$, respectively. They have $p$ values of $p<0.01$ when compared with control. This pattern of polymerization reduction is illustrated in Figure 1. Methanolic extract of Catharanthus roseus (Table 2 ) shows a significant reduction $(\mathrm{p}<0.01)$ in polymerization when applied to sodium metabisulfite induced polymerization of HbSS genotype erythrocytes. The reduction was to $75.02 \pm 0.54 \%, 85.82 \pm 0.35 \%$ and $86.32 \pm 0.15 \%$ at concentrations $10 \mathrm{ppm}, 5 \mathrm{ppm}$ and $2 \mathrm{ppm}$ respectively.

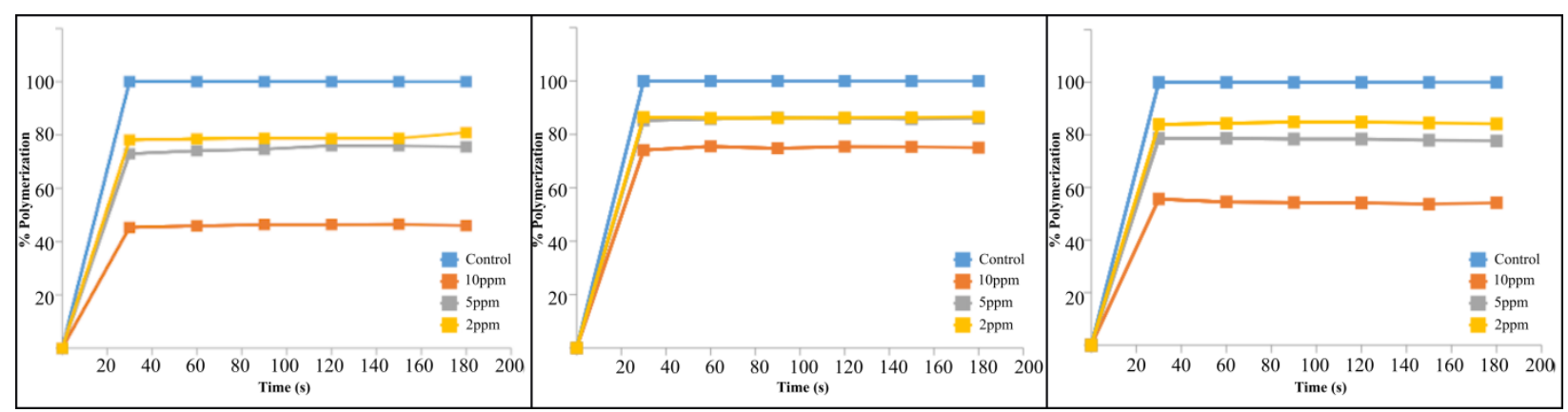

Figure 2: Percentage polymerization of erythrocyte hemolysate of HbSS genotype in the presence of methanolic extract of Hoslundia opposita, Catharanthus roseus and Rauvolfia vomitoria at three different concentrations.

Values are expressed as Mean \pm Standard deviation of mean. $n=5$. * $\mathbf{p}<0.01$ (When compared with control).

There was also a significant $(\mathrm{p}<0.01)$ reduction of polymerization of erythrocyte hemolysate of $\mathrm{HbSS}$ genotype in the presence of methanolic extract of Rauvolfia vomitoria vomitoria at different concentrations as presented in table 2. It reduces polymerization to $54.39 \pm 0.66 \%$, $78.30 \pm 0.39 \%$ and $84.49 \pm 0.36 \%$ for $10 \mathrm{ppm}, 5 \mathrm{ppm}$ and $2 \mathrm{ppm}$ respectively. In all there was an overall significant reduction of polymerization by the extracts of the different plant species tested. This goes to show that the plants have the ability to inhibit polymerization at different concentrations of 10ppm, $5 \mathrm{ppm}$ and $2 \mathrm{ppm}$.

Table 3: Percentage sickling of RBC in the presence of different concentrations of the five different extracts 


\begin{tabular}{|l|l|l|l|}
\hline & \multicolumn{1}{|c|}{$\mathbf{1 0 p p m}$} & \multicolumn{1}{|c|}{$\mathbf{5 p m}$} & \multicolumn{1}{|c|}{$\mathbf{p p m}$} \\
\hline Control & $51.10 \pm 6.80$ & $51.10 \pm 6.80$ & $51.10 \pm 6.80$ \\
\hline Hoslundia opposita & $16.12 \pm 2.10^{*}$ & $25.61 \pm 3.25^{*}$ & $19.60 \pm 2.54^{*}$ \\
\hline Catharanthus roseus & $27.47 \pm 6.17^{*}$ & $26.39 \pm 5.78^{*}$ & $22.57 \pm 2.19^{*}$ \\
\hline Rauvolfia vomitoria & $21.70 \pm 4.40^{*}$ & $21.12 \pm 4.02^{*}$ & $18.98 \pm 6.10^{*}$ \\
\hline Lantana camara & $36.79 \pm 5.72^{*}$ & $27.21 \pm 3.76^{*}$ & $20.42 \pm 2.53^{*}$ \\
\hline Euphorbia hirta & $31.74 \pm 3.74^{*}$ & $20.99 \pm 3.58^{*}$ & $25.61 \pm 9.27^{*}$ \\
\hline
\end{tabular}

Values are expressed as Mean \pm Standard deviation of mean. $n=5$.

${ }^{*} \mathrm{p}<0.01$ (When compared with control).

We obtained good dose-dependence for the polymerization assay in which the natural products in the different extracts have unfettered and direct access to the hemoglobin molecule and to the aggregation sites (Figure 3). In the sickling test however, this is not so: there is a layer of complexity, the natural barrier introduced by the plasma membrane (Table 3). This barrier constituted by the cell membrane in the sickling test most likely poses a pharmacokinetic challenge to the natural products, and prevents quite a number of their molecules from crossing into the RBC core where the hemoglobin molecules are located. Thus, the observed activity in the antisickling test (being cell based) is extensively modified by cell membrane penetration. 


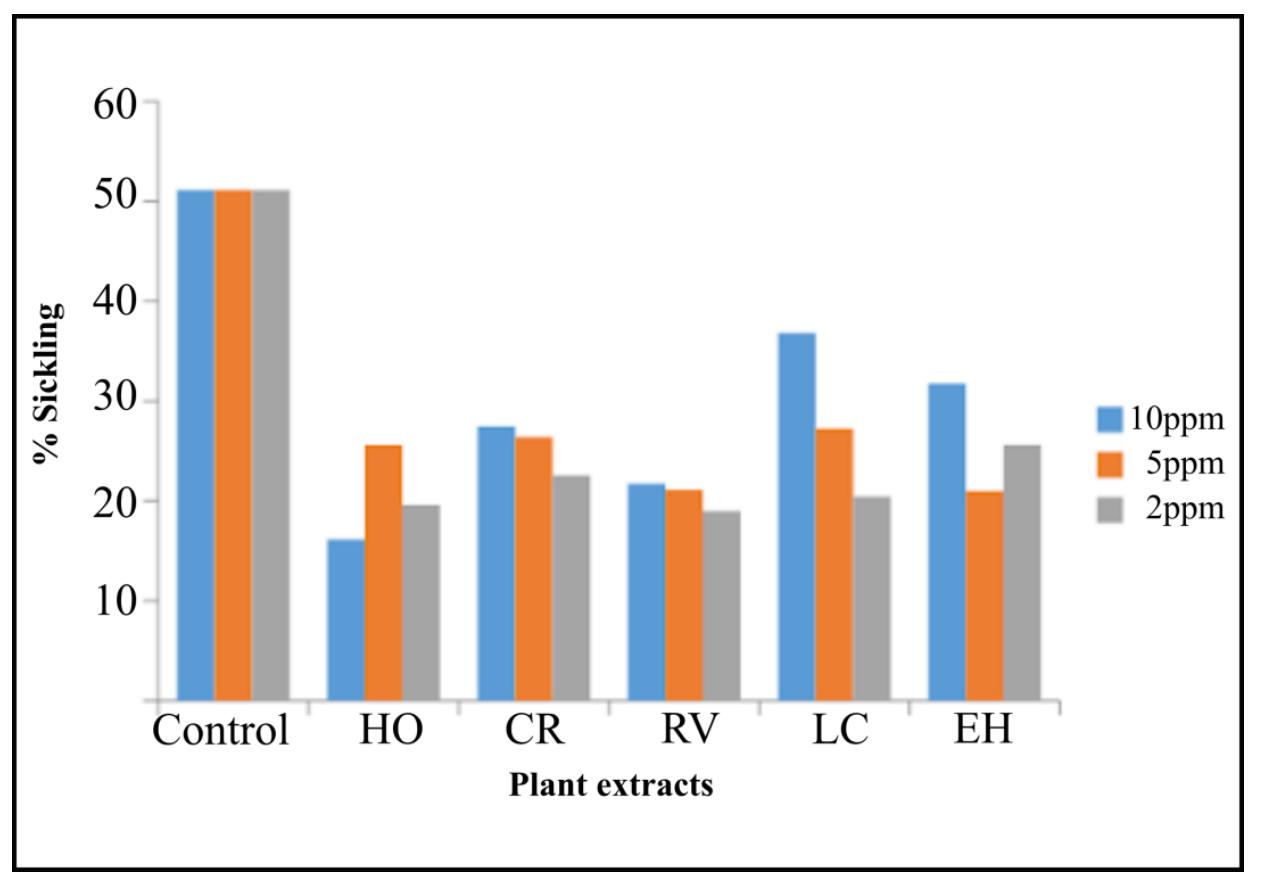

Figure 3: Percent Sickling of RBC in the presence of different plant extracts.

We believe that their polymerization inhibition capacity can be attributed to the phytochemicals earlier identified to be present in the various plant species and docked at the hydrophobic pocket of the HbS genotype. Hoslundia opposita contains the phytochemicals hoslunddiol, a flavonoids having binding energy of $-7.0 \mathrm{kcal} / \mathrm{mol}$. A close look at the structure of hoslunddiol reveals the presence of phenyl $\left(\mathrm{C}_{6} \mathrm{H}_{5}\right)$ group that helps to bind strongly at the hydrophobic pocket of the $\mathrm{HbS}$ genotype hence blocking the binding of valine to it. It also possesses a hydrophilic hydroxyl side chain that helps to disrupt the docking of Val6 on an incoming beta globin chain. This characteristic possessed by hoslunddiol is likely to be responsible for the antisickling activity displayed by the extract of Hoslundia opposita.

Similarly, Catharanthus roseus contains the phytochemical vinceine (ajmalicine), an alkaloid found in the leaves of the plant and having a binding energy of $-7.2 \mathrm{kcal} / \mathrm{mol}$. The structure of vinceine has a non-polar benzene $\left(\mathrm{C}_{6} \mathrm{H}_{6}\right)$ ring for binding and an acetate $\left(\mathrm{CH}_{3} \mathrm{COO}^{-}\right)$hydrophilic side chain helping to disrupt the docking of Val6 on an incoming beta globin chain. This is what is likely to be responsible for the antisickling activity shown by Catharanthus roseus.

Rauvolfia vomitoria has two phytochemicals of interest, astonine and corynanthine, both alkaloids with binding energy $-7.4 \mathrm{kcal} / \mathrm{mol}$ and $-7.2 \mathrm{kcal} / \mathrm{mol}$ respectively. Their structures both show the presence of a non-polar benzene $\left(\mathrm{C}_{6} \mathrm{H}_{6}\right)$ ring for binding and an acetate $\left(\mathrm{CH}_{3} \mathrm{COO}^{-}\right)$ hydrophilic side chain helping to disrupt the docking of Val6 on an incoming beta globin chain. This study reveals that, even though Alstonine has the lowest binding energy of $-7.4 \mathrm{kcal} / \mathrm{mol}$ compare to hoslunddiol with binding energy $-7.0 \mathrm{Kcal} / \mathrm{mol}$, Hoslundia opposita at 10ppm has a greater percentage $(53.93 \%)$ of polymerization inhibition compare to $45.61 \%$ and $25.46 \%$ polymerization inhibition of Rauvolfia vomitoria and catharanthus roseus. This could be likely due to the presence of more electronegative functional groups in alstonine thereby making it to 
have a more hydrophilic side chain that helps to disrupt the docking of Val6 on an incoming beta globin chain (Figure 4). Refer to table 1 for the structures of the phytochemicals of interest.

All five tested extracts show significant $(\mathrm{p}<0.01)$ reduction of sickling of red blood cells $(\mathrm{RBC})$ after inducing sickling with sodium metabisulfite. Methanolic extract of Hoslundia opposita shows a significant reduction of sickling after inducing sickling with sodium metabisulfite by $16.12 \pm 2.10,25.61 \pm 3.25$ and $19.60 \pm 2.54$ at concentrations $10 \mathrm{ppm}, 5 \mathrm{ppm}$ and $2 \mathrm{ppm}$ respectively when compare with control having a 51.10\% sickling. Methanolic extracts of Catharanthus roseus and Rauvolfia vomitoria also show a significant reduction in sickling by $27.47 \pm 6.17,26.39 \pm 5.78,22.57 \pm 2.19$ for $C$. roseus and $21.70 \pm 4.40,21.12 \pm 4.02,18.98 \pm$ 6.10 for Rauvolfia vomitoria at concentrations $10 \mathrm{ppm}, 5 \mathrm{ppm}$ and $2 \mathrm{ppm}$ respectively. Similarly, chloroform extract of Lantana camara L reduces percentage sickling of sickle red blood cells by $36.79 \pm 5.72,27.21 \pm 3.76$ and $20.42 \pm 2.53$ at concentrations $10 \mathrm{ppm}, 5 \mathrm{ppm}$ and $2 \mathrm{ppm}$ respectively. Chloroform extract of Euphorbia hirta also reduces percentage sickle of red blood cells when induced with sodium metabisulfite by $31.74 \pm 3.74,20.99 \pm 3.58$ and $25.61 \pm 9.27$ at concentrations $10 \mathrm{ppm}, 5 \mathrm{ppm}$ and $2 \mathrm{ppm}$ respectively.

Hoslundia opposita at 10ppm, 5ppm and 2ppm, reverse sickling of sickle red blood cells by $68.50 \%, 49.89 \%$ and $61.64 \%$ respectively Catharanthus roseus reverses sickling of sickle red blood cells by $46.24 \%, 48.35 \%$ and $55.84 \%$ at concentrations $10 \mathrm{ppm}, 5 \mathrm{ppm}$ and $2 \mathrm{ppm}$ respectively. Similarly, we observed that extract of Rauvolfia vomitoria shows a reversal in sickling of RBC by $57.53 \%, 58.67 \%$ and $62.85 \%$ for the three different working concentrations. There was also a reversal of sickling of sickle red blood cells by extracts of Lantana camara and Euphorbia hirta by $28.00 \%, 46.75 \%$ and $60.04 \%$ for L. camara and $37.88 \%, 58.92 \%$ and $49.88 \%$ for $E$. hirta at concentrations $10 \mathrm{ppm}, 5 \mathrm{ppm}$ and $2 \mathrm{ppm}$ respectively.

It is observed that the extracts show different capacity of sickling reversal at the different concentrations. For example, extract of $H$. opposita shows a greater percent $(68.50 \%)$ of sickling reversal at $10 \mathrm{ppm}$ and the least percent (49.89\%) at 5ppm. Catharanthus Roseus (L.) G.Don displayed a greater percent $(55.84 \%)$ of sickling reversal at $2 \mathrm{ppm}$ and shows the least percent $(46.24 \%)$ at $10 \mathrm{ppm}$. The highest percent sickling reversal for Rauvolfia vomitoria Afzel was observed at $2 \mathrm{ppm}$ (62.85\%) while the smallest was observed at $10 \mathrm{ppm}$ (57.53\%). Similarly, Lantana camara L displayed the least percent (28.00\%) of sickling reversal at 10ppm and the most percent $(60.04 \%)$ at $2 \mathrm{ppm}$ while extract of Euphorbia hirta L has the least percent $(37.88 \%)$ of sickling reversal at $10 \mathrm{ppm}$ and the most percent $(58.92 \%)$ at $5 \mathrm{ppm}$ (Table 3$)$.

A close look at Table 3 and Figure 3 shows that at 10ppm, extract of Hoslundia opposita Vahl has the highest percent of sickling reversal $(68.50 \%)$ when compared to others while extract of Lantana camara L shows the least percent sickling reversal (28.00\%). At 5ppm extract of Euphorbia hirta L shows the most percent (58.92\%) sickling reversal of sickle red blood cells while extract of Lantana camara L shows the least percent (46.75\%) sickling reversal. Similarly, extract of Rauvolfia vomitoria Afzel shows the most percent (62.85\%) sickling reversal of RBC at 2ppm while extract of Euphorbia hirta L shows the least percent (49.88\%) reversal of sickling of sickle red blood cells. The overall most significant reduction of sickling for the different extracts and concentration was observed for Hoslundia opposita Vahl (68.50\%) at 10ppm while the overall least percent $(28.00 \%)$ sickling reversal was observed for extract of Lantana camara L at $10 \mathrm{ppm}$. 


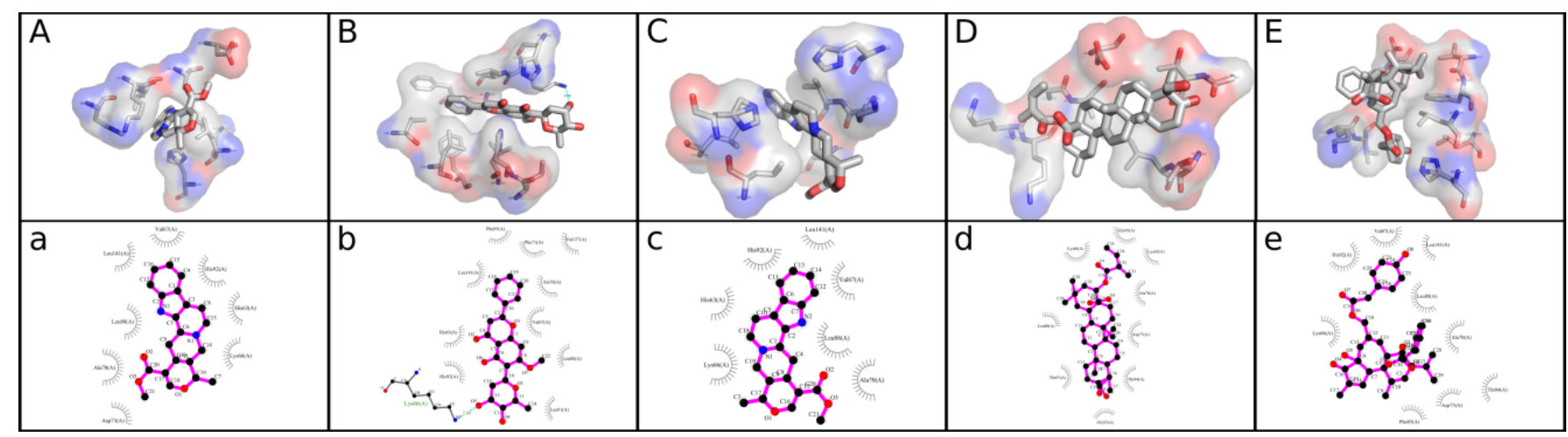

Figure 4: Interaction between the best compound from each of the five plants screened and the $\mathrm{HbS}$ receptor. The order of arrangement from left to right is: Alstonine, Hoslunddiol, Vinceine, Icterogenin and Tinyatoxin.

Lastly, we compared surface maps for the static molecular features of Glu and Val (Figure 5) which reveal subtle differences between both mutants that we believe underlie the distinctions in the aggregation behaviour of $\mathrm{HbA}$ and $\mathrm{HbS}$. From the presented electronic distribution, electrostatic and lipophilicity maps, the aggregation observed in $\mathrm{HbS}$ (and thus RBC sickling) is likely a consequence of the differences observed in the electrostatic and lipophilic features of Glu and Val. The pathologic Glu6Val mutation replaces an electron-rich glutamate side-chain capable of electrically preventing hydrophobic aggregation to a highly lipophilic valine side-chain that encourages aggregation. It is interesting to note that such seemingly minor shape and charge perturbation resulting from the point mutation is capable of provoking such far reaching structural and aggregational consequences that underlies SCD symptom complex. Perhaps the seemingly disproportionate conformational consequence of the mutation partly results from the allosteric nature of the hemologbin molecule which allows tiny changes to be amplified in processes downstream of the point of mutation. It is difficult to categorically state whether such influence also plays a part in the inhibitory action of the plant extracts studied in the present work. Analysis of the natural product-HbS interaction indeed reveals a good fit in Figure 4 and we believe that the inhibitory activities observed is at least partly a consequence of the interaction between the natural products and the investigated binding site of the sickle hemoglobin molecule. A categorical attribution of the inhibitory activities will however require a more detailed structural characterization of the binding event using spectroscopic characterization, especially X-ray spectroscopy. This is presently beyond the scope of this work whose aim is to present a procedure for employing natural products-based virtual screening in identifying plants with anti-sickling activities. 

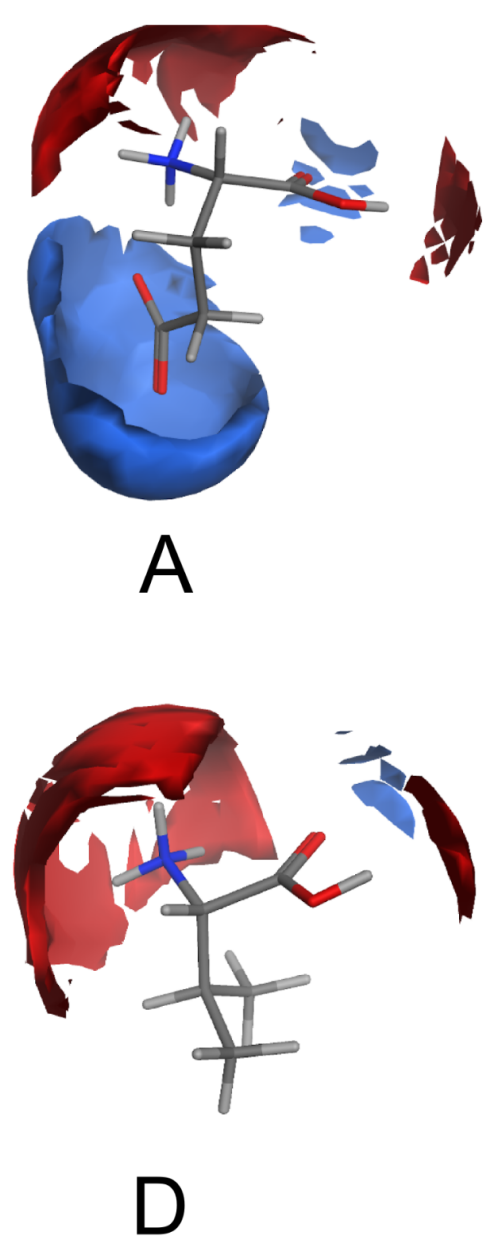
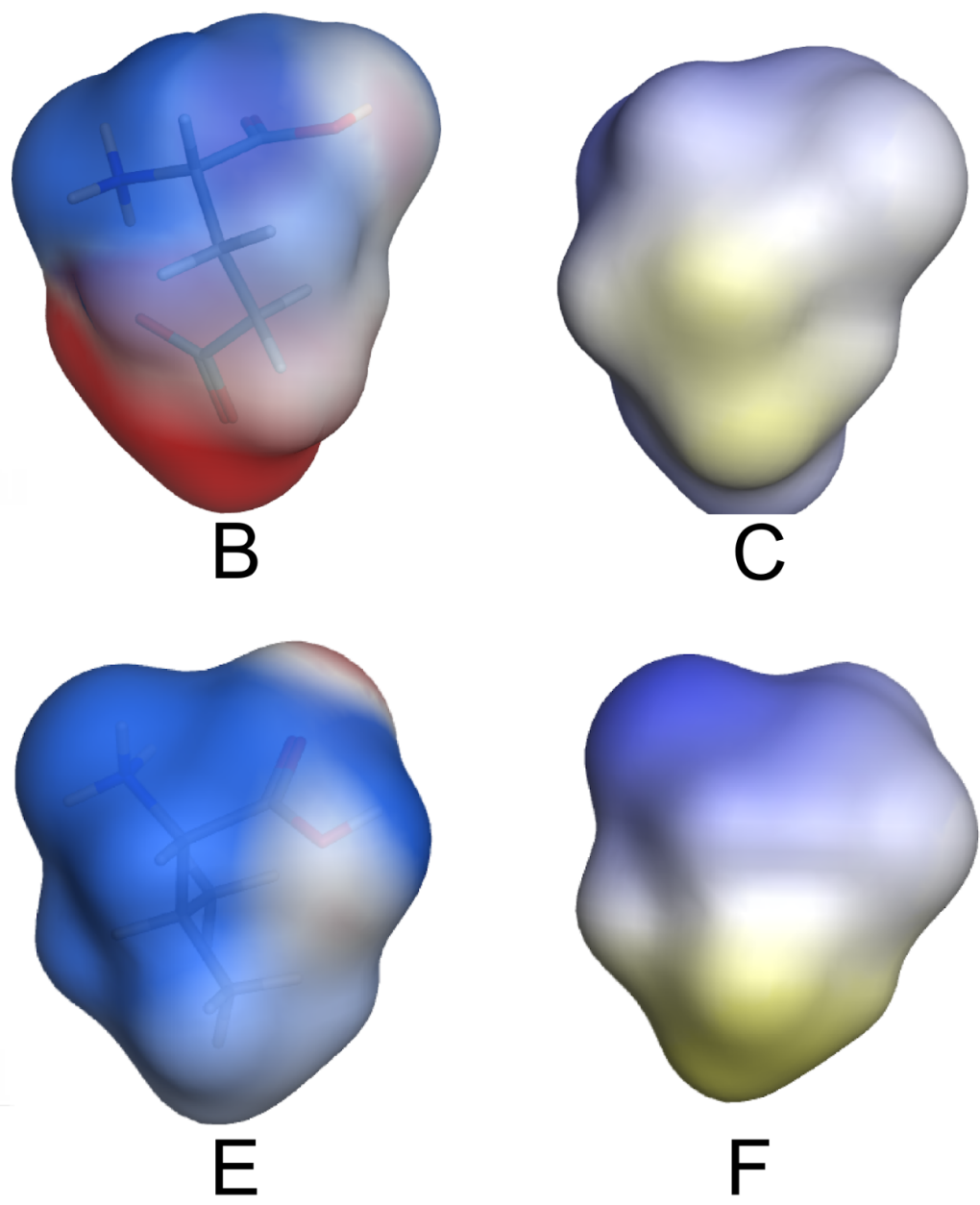

Figure 5: Surface maps comparing electronic charge distribution around Glu vs Val, electrostatic distribution lipophilicity surface maps of Glu vs Val. A.) Electronic charge interaction distribution around Glu showing positive charge preference around the carboxylate group. B.) Electrostatic potential distribution on Glu. C.) Lipophilicity surface map of Glu. D.) Electronic charge interaction distribution around Val. E.) Electrostatic potential distribution on Val. C.) Lipophilicity surface map of Val. Blue, red and light colors in electronic charge interaction and electrostatic potential maps indicate positive, negative and neutral charges, respectively; while light to yellowish color indicate increasing lipophilic nature in the lipophilic surface maps. The computed $\operatorname{LogP}(0 / w)$ values for zwitterionic glutamate and valine are $\mathbf{- 0 . 8 4 4}$ and 0.313 , respectively.

\section{Pharmacokinetics considerations}

It is important to consider that effects obtained in the cell-based antisickling experiment here likely has the involvement of pharmacokinetic contributions especially with respect to gaining access to the intracellular target. Focusing on the natural products with the best interaction with $\mathrm{HbS}$ we performed ADME modeling using the SwissADME web-based application (Daina and Zoete, 2016; Daina and Zoete, 2017) and focusing on gastrointestinal absorption as an indication of ability to cross cell membranes. Out of the 22 natural products so profiled, only threecalamene, icterogenin and toddalosin- were predicted to be associated with poor gastrointestinal 
(GIT) absorption. Apart from the three compounds being fairly strongly lipophilic (Log P ranging from 4.9 to 7.1 ), calamene is a hydrocarbon expected to be associated with aqueous solubility liabilities while the other two have molecular weights in excess of $500 \mathrm{~g} / \mathrm{mol}$. These features are likely responsible for the predicted defective absorption in the GIT. Transport across erythrocytic plasma membrane involves mobility across membrane bilayer essentially similar to that across the GIT epithelial cells and the predicted GI transport profiles may be taken to imply the compounds potential to cross RBC plasma membrane and gain access to intracellular HbS. Based on this nineteen natural products with high GI transport features are expected to attain intracellular concentrations sufficient for $\mathrm{HbS}$ aggregation. However, $50 \%$ of the compounds have the potential to cross the blood brain barrier (BBB) and might be associated with central nervous system effects. Even though it is only speculative what the role of P-glycoprotein (Pgp) binding will be in sickle cell disease drug management, we have included the Pgp interaction profiles for the natural products as their use would have implications in co-morbidities where Pgp inhibition is important. Majority of the natural products were predicted to possess Pgp inhibitory potential including hoslunddiol, icterogenin, vinceine, and tinyatoxin that are respective constituents of $H$. opposita, L. camara, C. roseus, and E. hirta tested in this work. We expect that this would have implications for the use of these natural products and the corresponding plants in SCD management involving (for example) cardiovascular comorbidities. It is interesting to note that alstonine (in R. vomitoria) was predicted to be unlikely to inhibit Pgp. We similarly obtained the predicted interaction profiles for five key metabolic enzymes (CYP1A2, CYP2C19, CYP2C9, CYP2D6, and CYP3A4) likely to influence their metabolic disposition as well as interaction with co-administered drugs or herbal products. Out of the five natural products found in the plants that we tested only the compound icterogenin (L. camara) shows zero likelihood of inhibiting any of the five cytochrome P450 enzymes. Hoslunddial $(H$. oposita) shows potential for inhibiting CYP3A4; vinceine (C. roseus) will likely inhibit CYP2D6, while alstonine ( $R$. vomitoria) shows possibility of inhibiting both enzymes as well as CYP2C19. Tinyatoxin was predicted with CYP2C9 and CYP3A4 inhibitory activity but none of the compounds was shown with predicted inhibitory action on CYP1A2. It however remains to be examined how these profiles will translate to clinical significance and if the titres of these natural products administered (e.g. in herbal preparations) constitute strong ground for meticulous pharmacotherapy review.

\section{Conclusion}

We have presented a protocol that employs virtual screening in identifying natural products with sufficiently strong interaction strength with the sickle hemoglobin. This guided our collection of plant parts and subsequent experimental testing of hemoglobin polymerization inhibitory activities as well as antisickling properties in whole cells. We have thus shown that, beyond the limitations imposed on ethnomedicinal research as a result of dependence on only ethnic knowledge and experience, our approach is capable, through screening of several natural products, of identifying plants with anti-sickling properties. It also has the advantage of achieving environmentally friendly lead finding research which assures the collection of only the plants with a good likelihood of producing desired pharmacological activities thereby reducing wastage of plant materials. Our approach has also helped us to gain time through screening of thousands of compounds within a short period. It is the first time deploying CADD for the identification of plants with antisickling activities in sickle cell disease research. The outcome of our work will be of importance both for development of new leads for SCD drug development. 


\section{Authors contributions}

Eric O. Olori: 3D Library Design, Virtual Screening, Plant Collection and In vitro testing. Writing- Original draft preparation. Olujide O. Olubiyi.: Conceptualization, 3D Library Design, Virtual Screening, Data curation, Writing-Original draft preparation, Editing. Chinedum P.

Babalola: Conceptualization, Project Planning and Supervision, Writing-Original draft preparation, Reviewing and Editing.

\section{REFERENCES}

1. Pauling L, Itano HA. Sickle cell anemia a molecular disease. Science. PubMed. 1949; 110:543-8.

2. Ingram VM. Gene mutations in human hemoglobin: The chemical difference between normal and sickle cell hemoglobin. PubMed. Nature. 1957; 180:326-8.

3. Piel FB, Patil AP, Howes RE, Nyangiri OA, Gething PW, Dewi M. Global epidemiology of sickle haemoglobin in neonates: a contemporary geostatistical model-based map and population estimates. Lancet. 2013;381:142-51

4. Bisnu PD et al. NCBI publication, Pharmacogn Rev, 2013; 7(13): 53-60.

5. Serjent GR. Homozygous sickle cell disease. 3rd Ed. New York: Oxford University Press; 2001. pp. 429-35.

6. Kar BC. Sickle cell disease in India. J Assoc Physicians India. 1991; 39:954-60.

7. Ferrone FA, Ivanova M, Jasuja R. Heterogeneous nucleation and crowding in sickle hemoglobin: An analytic approach. Biophys J. 2002, 82 (1), 399-406.

8. Ferrone FA, Hofrichter J, Eaton WA. Kinetics of sickle hemoglobin polymerization: II. A double nucleation mechanism. J. Mol. Biol. 1985, 183 (4), 611-631.

9. Abraham DJ, Perutz MF. Development of therapeutic agents for sickle cell disease. In: Approaches to the Therapy of Sickle Cell Anemia. INSERM, Paris. 1986, pp. 141-149.

10. Adachi K, Asakura T. Demonstration of delay time during aggregation of diluted solutions of deoxyhaemoglobin S and haemoglobin C Harlem in concentrated phosphate buffer. Journal of Biological Chemistry. 1978, 253, 6641-6643.

11. Adachi K, Asakura T. The solubility of sickle and non-sickle haemoglobins in concentrated phosphate buffer. Journal of Biological Chemistry. 1979a, 254, 4079-4084.

12. Adachi K, Asakura T. Nucleation-controlled aggregation of deoxyhaemoglobin S: Possible difference in the size of nuclei in different phosphate concentrations. Journal of Biological Chemistry. 1979b, 254, 7765-7771.

13. Adachi K, Asakura T. Kinetics of the polymerisation of haemoglobin in high and low phosphate buffers. Blood Cells, 1982, 8, 213-224.

14. Asakura T, Minakata K, Adachi K, Russell MO, Schwartz E. Denatured haemoglobin in sickle erythrocytes. Journal of Clinical Investigation. 1977, 59, 633-640.

15. Ballas SK. Neurobiology and treatment of pain. In: Sickle Cell Disease: Basic Principle and Clinical Practice. Raven Press, New York 1994. 
16. Charache S, Dover GJ, Moore RD, Eckert S, Ballas SK, Koshy M, Milner PF, Orringer EP, Philips JG, Platt OS, Thomas GH. Hydroxyurea: effects on Haemoglobin F production in patients with sickle cell anemia. Blood, 1992, 79, 2555-2565.

17. Eaton WA, Hofrichter J. Sickle cell haemoglobin polymerisation. In: Advances in Protein Chemistry Harcourt Brace Publishers, New York. (ed. by C.B. Anfinsen, J.T. Edsall, F.M. Richards \& D.S. Eisenberg), 1990 40, pp. 63-262.

18. Orringer EP, Abraham DJ, Parker JC. Development of drug therapy. In: Sickle Cell Disease: Basic Principle and Clinical Practice (ed. by S.H. Embury, R.P. Hebbel, N. Mohandas \& M.H. Steinberg). Raven Press, New York 1994.

19. Sunshine HR, Hofrichter J, Eaton WA. Requirement of the therapeutic inhibition of sickle cell $\mathrm{Hb}$ gelation. Nature, 1978 275, 238-240.

20. Wambebe C, Khamofu H, Momoh JA, Ekpeyong M, Audu BS, Njoku SO, Bamgboye EA, Nasipuri NR, Kunle OO, Okogun JI, Enwerem NM, Audam JG, Gamaliel SK, Obodozie OO, Samuel B, Fojule G, Ogunyale O. Double-blind placebo, randomised cross-over clinical trial of NIPRISAN in patients with sickle cell disorders. Phytomedicine, 2001a 8, 252-261.

21. Wambebe CO, Bamgboye EA, Bardu BO, Khamofu H, Momoh JA, Ekpeyong M, Audu BS, Njoku SO, Nasipuri NR, Kunle OO, Okogun JI, Enwerem NM, Gamaliel SK, Obodozie OO, Samuel B, Fojule G, Ogunyale PO. Efficacy of NIPRISAN in the prophylactic management of patients with sickle cell disease. Current Therapeutic Research. 2001b, 62, 26-34.

22. Olufunmilayo E, Adejumo AL, Kolapo OP, Roleola LS. Kasim. "In vitro antisickling activities and phytochemical evaluation of Plumbago zeylanica and Uvaria chamae. African Journal of Biotechnology 2010 Vol. 9(53), pp. 9032-9036

23. Sofowora EA, Isaacs WA. Reversal of sickling and crenation in erythrocytes by the root extract of Fagara zanthoxyloides. Lloydia. 1971, 34(4):383-385.

24. Thomas KD, Ajani B. Antisickling agent in an extract of unripe pawpaw fruit (Carica papaya) Transactions of the Royal Society of Tropical Medicine and Hygiene. 1987; 81(3):510-511.

25. Imaga NO, Gbenle GO, Okochi VI, et al. Antisickling property of Carica papaya leaf extract. African Journal of Biochemistry Research. 2009, 3(4):102-106.

26. Mpiana PT, Mudogo V, Kabangu YF, et al. Antisickling activity and thermostability of anthocyanins extract from a congolese plant, Hymenocardia acida Tul. (Hymenocardiaceae) International Journal of Pharmacology. 2009, 5(1):65-70.

27. Akinsulie AO, Temiye EO, Akanmu AS, Lesi FEA, Whyte CO. Clinical evaluation of extract of Cajanus cajan (Ciklavit) in sickle cell anaemia. Journal of Tropical Pediatrics. 2005, 51(4):200-205.

28. Fall AB, Vanhaelen-Fastré R, Vanhaelen $M$, et al. In vitro antisickling activity of a rearranged limonoid isolated from Khaya senegalensis. Planta Medica. 1999, 65(3):209-212

29. Ismaila ON, CO. Bewaji, JS. Johnson, Robertson DD, Yang Z. Potential of Three Ethnomedicinal Plants as Antisickling Agents. Mol Pharm. 2017, 14(1): 172-182.

30. Egunyomi A, Moody JO, Eletu OM. Antisickling activities of two ethnomedicinal plant recipes used for the management of sickle cell anaemia in Ibadan, Nigeria. African Journal of Biotechnology 2009, Vol. 8 (1), pp. 020-025 
31. Ugbor C. The effect of vegetable extracts on the antisickling potential of Aloe vera. 2006

32. Harrington DJ, Adachi K, Royer Jr,WE. The High Resolution Crystal Structure of Deoxyhemoglobin. S. J. Mol. Biol. 1997, 272, 398-407.

33. www.rcsb.org/pdb/home/home.do (accessed, July 9, 2016)

34. Moody JO, Segun FI, Aderounmu O, Omoade OO. Antisickling activity of Terminalia catappa leaves harvested at different stages of growth. Niger. J. Nat. Prod. Med. 2003, 7: //30-32. /

35. Noguchi CI, Schechter AN Inhibition of gelation by amino acids and related compounds. Biochemistry. 1978, 17: 5455-5459.

36. Chikezie PC. Sodium Metabisulfite-Induced Polymerization of Sickle Cell Hemoglobin Incubated in the Extracts of Three Medicinal Plants (Anacardium occidentale, Psidium guajava, And Terminalia catappa). Pharmacogn. Mag. 2011, 7, /126-132.

37. Ivanova M, Jasuja R, Kwong S, Briehl RW, Ferrone FA. Nonideality and the nucleation of sickle hemoglobin. Biophys J. 2000. 79:1016-22.

38. Ferrone FA, Ivanova M, Jasuja R. Heterogeneous nucleation and crowding in sickle hemoglobin: An analytic approach. Biophys. J. 2002, 82 (1), 399-406.

39. The Management of Sickle Cell Disease. National Heart Lung and Blood Institute. (NIH Publication No. 02-2117).

40. Iwu MN, Igboko AO, Onwubiko H, Ndu UE. Effect of Cajanus cajan on Gelation and Oxygen Affinity of Sickle Cell Hemoglobin. J. Ethnopharmacol. 1988, 20, 99-104.

41. National Heart, Lung, and Blood Institute. June 12, 2015

42. Rees DC, Williams TN, Gladwin MT. 2010, 376 (9757): 2018-31

43. www.wikipedia.org

44. The American Society of Health-System Pharmacists. 2016

45. Lanzkron S, Strouse JJ, Wilson R, et al. Ann. Intern. Med. 2008, 148 (12): 939-55

46. Klopper RR, Gautier L, Chatelain C, Smith GF, Spichiger R. Floristics of the angiosperm flora of sub-Saharan Africa: an analysis of the African plant checklist and database. Taxon 2007, 56, 201-208

47. Pharmcogn Rev. 2013, 7(13):53-60.

48. Sunday JA et al. Traditional Herbal Management of Sickle Cell Anemia: Lessons from Nigeria. 2012

49. Trott O, Olson AJ. Comput Chem. 2010, 31, 455-461.

50. Pauline N, Cabral BN. Anatole PC, Jocelyne MV, Bruno M, Jeanne NY. The in vitro antisickling and antioxidant effects of aqueous extracts Zanthoxyllum heitzii on sickle cell disorder. BMC Complementary Altern. Med. 2013, 13 (1), 162.

51. Sliwoski G, Kothiwale S, Meiler J, Lowe EW. Computational methods in drug discovery. Pharmacol Rev. 2013, 66(1):334-95

50. Olubiyi, OO, Olagunju MO, Oni JO, Olubiyi AO. Structural basis of antisickling effects of selected FDA approved drugs: A drug repurposing study. Curr. Comput. Aided Drug Des. 2018, 14, 106-116.)

51. Piel FB, Weatherall DJ. Sickle-cell disease: a call to action. Transactions of the Royal Society of Tropical Medicine and Hygiene. 2015, 109 (6), 355-356.

52. Olubiyi OO, Olagunju MO, Strodel B. Rational Drug Design of Peptide-Based Therapies for Sickle Cell Disease. Molecules. 2019, 24(24): 4551) 
53.Vichinsky E, Hoppe CC, Ataga KI, Ware RE, Nduba V, El-Beshlawy A, Hassab H, Achebe MM, Alkindi S, Brown RC et al. A Phase 3 Randomized Trial of Voxelotor in Sickle Cell Disease. N. Engl. J. Med. 2019, 381, 509-519.

54. Piel FB, Hay SI, Gupta S, Weatherall DJ, Williams TN. Global Burden of Sickle Cell Anaemia in Children under Five. 2010-2050: Modelling Based on Demographics, Excess Mortality, and Interventions. PLoS Med10. 2013. (7):e1001484.

55.Cousins KR. ChemDraw Ultra 9.0. CambridgeSoft, 100 CambridgePark Drive, Cambridge, MA 02140, J. Am. Chem. Soc., 127. 2005. 4115-4116.

56 Robert JO, David RJ. in Organic Chemistry, 2014.

57 Marengo-Rowe AJ. Structure- Function relations of human hemoglobins. Proceedings (Baylor University Medical Center), 2006. 19(3), 239-245.

58 Rogers DW, Clarke JM, Cupidore L, Ramlal AM, Sparke BR, Serjeant GR. Early deaths in Jamaican children with sickle cell disease, Br Med J. 1978, 1:1515-1516.

59 Vichinsky E, Hurst D, Earles A, Kleman K, Lubin B. Pediatrics Newborn screening for sickle cell disease: effect on mortality. PubMed 1988; 81(6):749-55

60 Almeida AM, Henthorn JS, Davies SC. Neonatal screening for haemoglobinopathies: the results of a 10-year programme in an English Health Region Br J Haematol. 2001, 112(1):32-5.

61 Bardakdjian MJ, Guilloud BM, Maier RM, Elion J, Girot R, Feingold J, Galactéros F, Montalembert M. Decreased morbidity in homozygous Hemoglobin sickle cell disease detected at birth. PubMed. 2002, 26(3):211-7

62 Lasch J, Küllertz G, Opalka JR. Separation of erythrocytes into age-related fractions by density or size Centrifugation Counterflow. Clin Chem Lab Med. 2000, 38(7):62

63 Disease and Injury Incidence and Prevalence Collaborators. GBD. 2015

64 Herrick JB. Peculiar elongated and sickle-shaped red blood corpuscles in a case of severe anemia.Yale. J Biol Med. 2001, 74(3):179-84.

65 Eaton WA, Hofrichter J. Hemoglobin S gelation and sickle cell disease. Blood. 1987, $70(5): 1245-66$

66 Levasseur DN, Ryan TM, Reilly MP, McCune SL, Asakura T, Townes TM. A recombinant human hemoglobin with anti-sickling properties greater than fetal hemoglobin. J Biol Chem. 2004, 279(26):27518-24

67 Abu S, Anyaibe S. Chromatographic fractionation of anti-sickling agents in Fagara xanthoxyloides. Headings V Acta Haematol. 1981, 66(1):19-26

68 Osuagwu CG. Mechanism of the anti-sickling effects of Cajanus cajan and Phenylalanine. Nigerian J Biochem Mol Bio. 2010, 25:68-71.

69 Piel FB, Patil A, Howes R et al. Global epidemiology of Sickle haemoglobin in neonates. The Lancet. 2013a, 381(9861):142-151

70 Piel FB, Hay SI, Gupta S, et al. Global Burden of Sickle Cell Anaemia in Children under Five, 2010-2050. 2013b;10(7):e1001484.

71 Piel FB, Steinberg MH, Rees DC. Sickle Cell Disease. The New England Journal of Medicine. 2017, 376(16):1561-1573.

72 Daina A, Michielin O, Zoete V. SwissADME: a free web tool to evaluate pharmacokinetics, drug-likeness and medicinal chemistry friendliness of small molecules. Scientific Reports 7(42717).

73 Daina A, Zoete V. A BOILED-Egg to predict gastrointestinal absorption and brain penetration of small molecules. ChemMedChem 2016. 11(11): 1117-1121. 